\title{
A questão do petróleo no Brasil: reflexões sobre o cenário atual
}

\section{Mariana Ribeiro Fernandes}

\section{(2) OpenEdition \\ 1 Journals}

\section{Edição electrónica}

URL: https://journals.openedition.org/espacoeconomia/833

DOI: 10.4000/espacoeconomia.833

ISSN: 2317-7837

\section{Editora}

Núcleo de Pesquisa Espaço \& Economia

\section{Refêrencia eletrónica}

Mariana Ribeiro Fernandes, «A questão do petróleo no Brasil: reflexões sobre o cenário atual», Espaço e Economia [Online], 4 | 2014, posto online no dia 11 setembro 2014, consultado o 21 setembro 2021. URL: http://journals.openedition.org/espacoeconomia/833 ; DOI: https://doi.org/10.4000/ espacoeconomia.833

Este documento foi criado de forma automática no dia 21 setembro 2021.

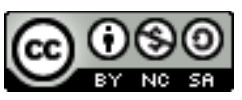

Espaço e Economia - Revista brasileira de geografia econômica est mise à disposition selon les termes de la licence Creative Commons Attribution - Pas d'Utilisation Commerciale - Partage dans les Mêmes Conditions 4.0 International. 


\title{
A questão do petróleo no Brasil: reflexões sobre o cenário atual
}

\author{
Mariana Ribeiro Fernandes
}

\section{REFERÊNCIA}

MONIÉ, Frédéric; BINSZTOCK, Jacob (Orgs). Geografia e Geopolítica do Petróleo. Rio de Janeiro: Mauad, 2012.

\section{NOTA DO EDITOR}

Esta resenha é parte do Projeto de Pesquisa coordenado pelo Prof. Dr. Leandro Dias de Oliveira intitulado "A Reestruturação Territorial-Produtiva no Oeste Metropolitano Fluminense", com o apoio da FAPERJ - Fundação Carlos Chagas de Amparo à Pesquisa do Estado do Rio de Janeiro.

\section{NOTA DO AUTOR}

Agradecemos ao Prof. Dr. Leandro Dias de Oliveira, orientador da monografia de final de curso de Graduação em Relações Internacionais na UFRRJ, pela colaboração nesta resenha.

1 A presente resenha destaca a contribuição da obra organizada pelos geógrafos Fréderic Monié e Jacob Binsztock sobre o tema do petróleo. Este tema carrega extrema relevância política e econômica desde que o petróleo tornou-se o principal combustível da matriz energética mundial, isto é, durante o século XX (COSTA, 2012, p. 56). Além do mais, desde 2000 fatores de cunho geopolítico aumentam o sentimento de insegurança energética das nações (MONIÉ, 2012, p.211). 
2 Geografia e Geopolítica do Petróleo é composto por uma coletânea de artigos que abordam a questão do petróleo não de maneira técnica, mas política: as implicações deste no comércio nacional e internacional, a garantia de fontes petrolíferas no status de potência e nas estratégias estatais, bem como os impactos domésticos que uma descoberta de jazida petrolífera pode causar para o Estado que a encontra.

3 Assim como o petróleo pode ser considerado, de certa forma, um produto universal, o tema é tratado no livro de maneira que abrange diversas escalas: o global, o regional e, por fim, o local. Já na introdução, deparamo-nos com o ponto de encontro entre o ouro negro e a área de Relações Internacionais, identificado pelos autores por meio da Teoria Liberal de RI, e também por meio do posicionamento do Ministério das Relações Exteriores com relação ao tema.

4 A primeira parte da obra enriquece a bagagem cultural do leitor com um breve histórico do uso do petróleo como recurso artesanal até o enorme complexo industrial petrolífero da atualidade [A evolução da indústria petrolifera: uma caracterização geral, por Pierre Costa]. Também nesta parte, há uma reflexão sobre a geoeconomia e as multinacionais do setor [Geoeconomia e integração regional na América do Sul, por Cláudio Antonio Gonçalves Egler e Margarida Maria C. L. Mattos], bem como é realizada uma relação entre espaço geográfico e regulação [Petróleo e gás natural: de fronteira em fronteira, do espaço às superfícies de regulação, por Gisela Aquino Pires do Rio]. A segunda parte elucida o leitor sobre os tipos de situações embaraçosas que um Estado exportador dessa commodity pode enfrentar, abordando ainda as questões do desenvolvimento regional [Petróleo e desenvolvimento regional no Brasil, por Rosélia Piquet] e a dos tão polêmicos royalties [Petróleo, royalties e desenvolvimento: Brasil e experiências internacionais, por Rodrigo Valente Serra e Sérgio Wulff Gobetti].

5 Na terceira parte, os Capítulos 7 [Petróleo, desenvolvimento e dinâmicas espaciais na África Subsaariana] e 8 [O novo "grande jogo" e a geopolítica dos oleodutos no Mar Cáspio], de autoria de Fréderic Monié, apresentam abordagens sobre as dinâmicas mundiais e as ações dos Estados de acordo com a disponibilidade e acesso ao minério precioso, isto é, o novo mapa mundial do petróleo. Por fim, em conformidade com o que assinalou Monié (2014, p. 221) sobre a importância de se analisar o boom petrolífero em diversas escalas, a quarta e última parte da obra resenhada traz, com artigos de Jacob Binsztock, informações valiosas sobre os impactos ocorridos nas cidades do estado do Rio de Janeiro, em virtude da descoberta do pré-sal na região [Capítulos 9 a 13, a saber: A cidade do Rio de Janeiro e a cadeia produtiva de petróleo e Exploração de petróleo e modificações socioespaciais em Macaé: dilemas e perspectivas, por Jacob Binsztock; Considerações sobre o Complexo Petroquímico do Rio de Janeiro (Comperj) e sua região, por Jacob Binsztock e Julio Cezar Wasserman; A reestruturação econômica e territorial do Norte Fluminense, por Denise Cunha Tavares Terra, Elzira Lúcia de Oliveira e Gustavo Henrique Naves Givisiez; e ainda, O mapa da riqueza e da pobreza nas cidades do petróleo no estado do Rio de Janeiro, por Elzira Lúcia de Oliveira e Gustavo Henrique Naves Givisiez].

6 Este livro chega em momento oportuno, pois, em 2013, comemorou-se 60 anos de existência da Petrobras e completou-se 40 anos do choque do petróleo de 73. Naquele contexto de crise, os países periféricos produtores de petróleo utilizaram-no como "arma estratégica política" contra países centrais, apesar do custo alto dessa ação para os próprios produtores, como ressaltou Brito, et. al. (2012, p.32). Também é momento oportuno porque se discutiu, em 2010, a regulação brasileira sobre a repartição dos royalties, a consolidação de centros de pesquisas e leilões para exploração dos campos 
do pré-sal e, por fim, as políticas públicas acerca das jazidas de petróleo recentemente descobertas na plataforma continental brasileira.

7 Como demonstrou Pierre Costa (2012), a história da ascensão do petróleo como fonte energética global não pode ser pensada sem consultarmos um mapa dos EUA. Sendo assim, o autor divide tal história em duas fases: inicialmente com a descoberta da propriedade energética do produto e sua comercialização e industrialização domesticamente nos EUA. Na segunda fase vemos o aumento do consumo do mesmo em escala global, o início da produção industrial em outras regiões (como no Oriente Médio), o surgimento das primeiras majors internacionais e, por fim, o surgimento de mercados regionais que passaram a compor o mercado internacional (COSTA, 2012, p. 70). relação intrínseca entre este produto e a ascensão do capitalismo e da hegemonia estadunidense. A expansão da economia ianque desde os primórdios das treze colônias até os dias atuais (PORTO-GONÇALVES, 2013) e as atitudes de tendência imperialista praticadas pelos EUA no Oriente Médio constituem verdadeiros exemplos desta relação estreita com o petróleo (HARVEY, 2013).

9 No Brasil, diferentemente dos países centrais, a história do setor petrolífero não se inicia com a introdução do petróleo nas atividades econômicas aqui existentes, mas a própria construção do sistema energético nacional foi pensada visando impulsionar a industrialização nacional (COSTA, 2012, p. 60).

10 Egler e Mattos (2012, p. 83) comentam o conhecimento compartilhado entre Economia e Geografia ao ressaltar que as recentes descobertas de jazidas na América do Sul (Brasil, Argentina e Venezuela) aumentaram a importância do papel desse continente no mercado mundial de petróleo. A partir das duas lógicas existentes na dinâmica espacial por estudos anteriores - onde na primeira lógica os governantes territorialistas concebem a expansão territorial como fonte de riqueza e, na segunda, os governantes capitalistas relacionam o poder com a extensão do controle sobre recursos escassos -, Egler e Mattos (2012, p.87) destacam que também a Geopolítica e Geoeconomia possuem significado duplo: são ferramentas de análise para interpretar, a partir da lógica da acumulação, o espaço econômico e são também instrumento do Estado para aumentar seu poder estratégico diante da concorrência global por mercados.

11 A geoeconomia instrumentalizada pelos três Estados analisados (Venezuela, Argentina e Brasil) encontra-se, de certa forma, equilibrada entre dois caminhos: em parte impera a busca pelos objetivos estatais diversos, por diferentes estratégias de longo prazo e interesses diferenciados, que privilegiam a face independente das estatais petrolíferas e dos próprios Estados e sua aspiração à liderança regional. Por outro lado, existe a questão da responsabilidade regional e integração que interessa a esses e os demais países do continente, apesar das diferentes condicionantes históricas de cada um dos três países (EGLER e MATTOS, 2012).

12 A Petrobras, no atual contexto energético internacional de escassez do petróleo de fácil acesso, encontra-se em posição de liderança não apenas no continente sulamericano como também tende a ser em nível global. Isto é possível, devido à tecnologia de ponta adquirida pela estatal por meio de investimentos estatais ao longo dos últimos anos. Outro fator que coloca a Petrobras em vantagem é ampliação de seu setor de atuação, pela qual a empresa passou a atuar nos setores das demais fontes de energia, o que levou a centralização da estratégia energética do Estado (EGLER e MATTOS, 2012). 
Embora o Ministério das Relações Exteriores priorize o etanol e utilize o segmento de energia para aumentar a inserção brasileira no cenário internacional principalmente na questão ambiental e climática (BRITO et. al. 2012, p.41); essa ampliação efetuada pela estatal, em parte, está em conformidade com as aspirações deste Ministério que previam a importância dos demais setores de energia no cenário global atual, além de não perder de vista o potencial das jazidas da plataforma continental brasileira e de não permitir que outras companhias explorassem este produto altamente poluente, mas ainda extremamente importante na geoeconomia dos Estados.

Articulando as dimensões geopolítica, geoeconômica e geoinstitucional, Pires do Rio (2012) possibilita conceber o cenário energético brasileiro que envolve, inclusive, conflitos relacionados às regulações e à gestão do pré-sal da plataforma continental brasileira, onde convergem regulações das atividades petrolíferas, dos recursos hídricos e de meio-ambiente (PIRES DO RIO, 2012, p.117). Sobre a reflexão que permeia os debates acerca do tema, relacionada ao fato de a descoberta do pré-sal constituir-se ou não em retrocesso na busca de diversificação da matriz energética e nas questões ambientais, Pires do Rio (2012, p.112) ressalta que as novas fronteiras de petróleo e gás brasileiras parecem indicar direção oposta à tendência internacional de substituição destes por fontes de energia menos poluidoras.

Os capítulos da segunda parte da obra estão direcionados a conceder contribuições extremamente pertinentes no tocante à relação petróleo - desenvolvimento. Neste sentido, Periard e Losekann (2012) alertam para o risco de um país produtor do "ouro negro" cair na chamada Maldição dos Recursos Naturais (MRN) ${ }^{1}$ e descrevem de maneira esclarecida os diversos impactos negativos da abundância de petróleo. Abordam (Idem, p. 131) ainda três variáveis que descrevem o grau da participação petrolífera na economia de um Estado: a participação das exportações de petróleo na pauta de exportações, o percentual da renda petrolífera sobre o total da renda do governo e o percentual do setor extrativista mineral sobre o PIB dos principais países produtores de petróleo.

Da mesma maneira, para tais efeitos há uma gama de possíveis medidas para evitar que um Estado seja acometido pela MRN. Em síntese, tais medidas podem ser separadas em quatro grupos: Planejamento do ritmo de produção, diversificação econômica, esterilização dos capitais externos e criação de fundos soberanos e, por fim, fortalecimento do accountability e maior responsabilização nas instituições democráticas (PERIARD e LOSEKANN, 2012, p.1 40-143).

Entendemos que, de certa forma, o Brasil tem seguido as tendências de tais medidas, principalmente por meio da criação do Fundo Social do Pré-Sal e do Programa Ciências sem Fronteiras, por exemplo. Contudo, tanto o Fundo Social quanto o Programa CsF, de inspiração norueguesa ${ }^{2}$, foram criados a partir da maior relevância que é atribuída a tais temas - (i) a quem pertence a renda proveniente dos recursos naturais nacionais e (ii) especialização da mão-de-obra - em detrimento da menor importância dada ao debate acerca da diminuição do empenho governamental nas políticas públicas de preservação ao meio ambiente e aumento deste empenho a favor da cadeia setorial de petróleo e gás, contradição destacada por Piquet (2012, p. 146 e 161). Afinal, quanto maior o nível de desenvolvimento do capital humano, maior a probabilidade de haver crescimento, como destacou Monié (2012, p. 219).

Além disso, cabe ressaltar que a luta social brasileira acerca desse setor tem sua importância devido ao fato de ser o agente fundamental e principal interessado no 
último e quarto grupo de medidas [fortalecimento do accountability e maior responsabilização nas instituições democráticas] apontadas por Periard e Losekann (2012, p. 140-143); não podendo ser atenuada a sua contribuição ao longo do séc. XX (MIRANDA, 2005) e nem a importância de seu papel e participação na situação atual e futura. Portanto, outra questão a ser lembrada é o apelo social basilar da estatal brasileira Petrobras, comentado em trabalho anterior (FERNANDES, 2014, p. 48).

Sendo assim, como avaliar os impactos dos empreendimentos da indústria petrolífera no Brasil? Piquet (2012) apresenta uma abordagem que ampara a metodologia das análises dos impactos da indústria petrolífera, baseando-se principalmente em Alejandro Rofman. A autora reitera: "não é trivial a avaliação desses impactos, uma vez que sua influência ultrapassa em muito a esfera local/regional e [...] dificilmente sua influência irá limitar-se a espaços subnacionais" (PIQUET, 2012, p. 160). A autora alerta também para o fato de que os impactos negativos são capciosamente de baixa repercussão nacional (Idem, p. 161). Por fim, Piquet avalia tais impactos na região de Macaé, cidade do litoral norte do estado do Rio de Janeiro.

19 Serra e Gobetti (2012, p.172) fazem uma análise crítica propositiva sobre as regras nacionais de distribuição e aplicação das rendas petrolíferas no Brasil. Regras essas que deveriam, entre outras constatações normativas dos autores, reconsiderar a ideia de conceber como destino das rendas petrolíferas os municípios geograficamente confrontantes com as reservas do solo nacional e da plataforma continental. o destino de tais rendas deveria ser pulverizado de forma mais equânime entre todos os estados e municípios do país. Os autores ainda apontam outras lacunas sobre a atual regulação, que incluem, por exemplo, a questão tributária. E apresentam sinteticamente um relato da questão regulatória sobre o setor em outras federações em que o petróleo tem enorme contribuição em sua economia (Malásia, México, Nigéria, Rússia, Venezuela), e também naquelas federações em que esta participação não é tão significativa (Argentina, Austrália, Brasil, Canadá, EUA, Índia e Paquistão). A partir desta relação de experiências, os autores indicam magistralmente qual seria o melhor caminho que a regulação e gestão fiscal brasileira deveriam seguir para além da simples mudança recentemente ocorrida [2010] do regime de concessão para o regime de partilha.

Em seguida, a terceira parte da obra trata do atual mapa mundial do petróleo, isto é, o novo jogo petrolífero mundial com a dinâmica da globalização e da inserção de novas regiões (como a África Subsaariana) ocorrida neste jogo nas últimas décadas, a partir da qual a indústria petrolífera foi reestruturada pelas estratégias desenvolvidas pelos países centrais, emergentes e consumidores (MONIÉ, 2012, p.211). O autor ainda apresenta uma descrição da relação petróleo-desenvolvimento na África subsaariana, onde a ocorrência do primeiro não levou exatamente ao segundo, o que nos induz a questionar se há grande diferença da situação brasileira sobre esse mesmo aspecto.

21 Da mesma forma, agora sobre o caso da geopolítica dos oleodutos do Mar Cáspio, cada um dos Estados envolvidos, mas principalmente os governos recém-emancipados (da ex-URSS) da região, valeram-se de estratégias que concebiam o petróleo (e o setor energético como um todo) como vetor de desenvolvimento. Assim, os diversos atores envolvidos no setor petrolífero - desde ONGs internacionais até sociedades civis organizadas -, são impulsionados a agir por meio de um conceito de Mazzen Labban chamado geopolítica híbrida. Geopolítica em que os atores envolvidos, possuem em suas estratégias duas lógicas concomitantes: a lógica da cooperação e a da competição. Por isso, em alguns momentos, os casos que envolvem petróleo atribuem maior 
relevância ao "custo estratégico" de alguma tomada de decisão e menor relevância ao seu custo financeiro (MONIÉ, 2012).

Em suma, a obra aqui resenhada constitui-se parte fundamental da bibliografia sobre petróleo, interessando a todos que pretendem pensar e analisar não apenas a Geopolítica e Geografia do petróleo, mas também a Geoeconomia ${ }^{3}$ energética brasileira, um estudo que se faz cada vez mais relevante. Afinal, o petróleo é concebido como vetor de desenvolvimento, como fonte de renda governamental, como instrumento de poder na arena internacional e, porém, é paradoxalmente integrante das principais causas de degradação ambiental mundial; o que, principalmente pela geopolítica do desenvolvimento sustentável (OLIVEIRA, 2011), constitui-se numa contrapartida que retarda a superação do subdesenvolvimento por parte dos países "não-centrais".

Além do mais, a expansão da indústria em escala nacional está em conformidade com a constatação de Lefevbre (2006, p. 141), a qual entende que a organização da indústria moderna produziu explosão da morfologia tradicional das cidades e, nesta experiência prática assistida mundialmente, ficou claro que o crescimento econômico nos centros urbanos não é, necessariamente, desenvolvimento social, com inúmeras pessoas sem seu chamado "direito a cidade", como demonstra a última parte da obra resenhada [Capítulos 9 a 13] acerca dos impactos sofridos por cidades do Rio de Janeiro com o advento e crescimento da indústria petrolífera.

Sendo o petróleo uma mercadoria de primeira grandeza extremamente vinculada às relações de poder em escala mundial, e o Brasil, progressivamente, se habilitando como importante produtor e mesmo player no mercado internacional de petróleo, é de fato um momento muito oportuno para que se faça uma reflexão política sobre o seu potencial petrolífero e as formas de gestão do mesmo. Este tema - a rigor, o tema da energia em seus mais variados tipos - e sua ligação com assuntos como meio-ambiente, geração de empregos, fomento de tecnologia e progresso, é um campo com ampla oportunidade a ser explorado pelas ciências humanas em todas as sua variações e complexidades.

\section{BIBLIOGRAFIA}

BINSZTOCK, Jacob. A cidade do Rio de Janeiro e a cadeia produtiva de petróleo. In: MONIÉ, Frédéric; BINSZTOCK, Jacob (Orgs). Geografia e Geopolítica do Petróleo. Rio de Janeiro: Mauad, 2012. BINSZTOCK, Jacob. Exploração de petróleo e modificações socioespaciais em Macaé: dilemas e perspectivas In: MONIÉ, Frédéric; BINSZTOCK, Jacob (Orgs). Geografia e Geopolítica do Petróleo. Rio de Janeiro: Mauad, 2012.

BINSZTOCK, Jacob; WASSERMAN, Julio Cezar. Considerações sobre o Complexo Petroquímico do Rio de Janeiro (Comperj) e sua região In: MONIÉ, Frédéric; BINSZTOCK, Jacob (Orgs). Geografia e Geopolítica do Petróleo. Rio de Janeiro: Mauad, 2012.

COSTA, Pierre. A evolução da indústria petrolífera: uma caracterização geral. In: MONIÉ, Frédéric; BINSZTOCK, Jacob (Orgs). Geografia e Geopolítica do Petróleo. Rio de Janeiro: Mauad, 2012. 
EGLER, Cláudio Antonio Gonçalves; MATTOS, Margarida Maria C. L. Geoeconomia e integração regional na América do Sul. In: MONIÉ, Frédéric; BINSZTOCK, Jacob (Orgs). Geografia e Geopolítica do Petróleo. Rio de Janeiro: Mauad, 2012.

FERNANDES, Mariana Ribeiro. Brasil e Noruega: uma análise sobre a cooperação petrolífera, 2014. 69 p. Monografia em Relações Internacionais - Instituto de Ciências Humanas e Sociais, Universidade Federal Rural do Rio de Janeiro (UFRRJ), Seropédica - RJ.

GIVISIEZ, Gustavo Henrique Naves; OLIVEIRA, Elzira Lúcia de. O mapa da riqueza e da pobreza nas cidades do petróleo no estado do Rio de Janeiro In: MONIÉ, Frédéric; BINSZTOCK, Jacob (Orgs). Geografia e Geopolítica do Petróleo. Rio de Janeiro: Mauad, 2012.

HARVEY, David. O Novo Imperialismo. $7^{\text {a }}$ ed. São Paulo: Loyola, 2013.

LEFEBVRE, Henri. O Direito à Cidade. São Paulo: Centauro, 2006 (1973).

MIRANDA, Maria Augusta Tibiriçá. o petróleo é nosso: a luta contra o "entreguismo", pelo monopólio estatal. 2ed. São Paulo: Editora IPSIS, 2004.

MONIÉ, Frédéric. O novo "grande jogo" e a geopolítica dos oleodutos no Mar Cáspio. In: MONIÉ, Frédéric; BINSZTOCK, Jacob (Orgs). Geografia e Geopolítica do Petróleo. Rio de Janeiro: Mauad, 2012.

MONIÉ, Frédéric. Petróleo, desenvolvimento e dinâmicas espaciais na África Subsaariana In: BINSZTOCK, Jacob (Orgs). Geografia e Geopolítica do Petróleo. Rio de Janeiro: Mauad, 2012.

OLIVEIRA, Leandro Dias de. A geopolítica do desenvolvimento sustentável: um estudo sobre a Conferência do Rio de Janeiro (Rio-92), 2011. 283 p. Tese (Doutorado) - Instituto de Geociências, Universidade Estadual de Campinas (UNICAMP), Campinas - SP.

PERIARD, Thiago; LOSEKANN, Luciano. Petróleo, doença holandesa e dependência da renda petrolífera. In: MONIÉ, Frédéric; BINSZTOCK, Jacob (Orgs). Geografia e Geopolítica do Petróleo. Rio de Janeiro: Mauad, 2012.

PIQUET, Rosélia. Petróleo e desenvolvimento regional no Brasil. In: MONIÉ, Frédéric; BINSZTOCK, Jacob (Orgs). Geografia e Geopolítica do Petróleo. Rio de Janeiro: Mauad, 2012.

PIRES DO RIO, Gisela Aquino. Petróleo e gás natural: de fronteira em fronteira, do espaço às superfícies de regulação. In: MONIÉ, Frédéric; BINSZTOCK, Jacob (Orgs). Geografia e Geopolítica do Petróleo. Rio de Janeiro: Mauad, 2012.

PORTO-GONÇALVES, Carlos Walter. A Globalização da Natureza e a Natureza da Globalização. Rio de Janeiro: Civilização Brasileira, 2006.

SERRA, Rodrigo Valente; GOBETTI, Sérgio Wulff. Petróleo, royalties e desenvolvimento: Brasil e experiências internacionais. In: MONIÉ, Frédéric; BINSZTOCK, Jacob (Orgs). Geografia e Geopolítica do Petróleo. Rio de Janeiro: Mauad, 2012.

TERRA, Denise Cunha Tavares; OLIVEIRA, Elzira Lúcia de; GIVISIEZ, Gustavo Henrique Naves. A reestruturação econômica e territorial do Norte Fluminense In: MONIÉ, Frédéric; BINSZTOCK, Jacob (Orgs). Geografia e Geopolítica do Petróleo. Rio de Janeiro: Mauad, 2012.

\section{NOTAS}

1. MRN é o nome dado ao paradoxo no qual "a riqueza das reservas de petróleo não é convertida em bem-estar para a população" (PERIARD e LOSEKANN, 2012, p.127).

2. Ver FERNANDES (2014, p.45 e 49) 
3. Especialmente nos segmentos da Geoeconomia listados a seguir: "a Geoeconomia dedica-se à análise [1] do efeito dos fluxos supranacionais sobre a segurança territorial, [2] dos impactos da lógica de mercado sobre a segurança social e da "ressignificação" do Estado nacional como agente geoeconômico, e [3] da superimposição da lógica privada, por exemplo, na adoção de políticas de desenvolvimento (PIRES DO RIO, 2012, p. 106).

\section{AUTORES}

\section{MARIANA RIBEIRO FERNANDES}

Bacharel em Relações Internacionais pela UFRRJ - Universidade Federal Rural do Rio de Janeiro. Membro do Grupo de Pesquisa "Reestruturação Espacial Contemporânea" [DEGEO / UFRRJ].

E-mail: maryrifer@yahoo.com.br 